\title{
Espectroscopia - algumas ideias
}

\section{Parte I}

\section{Prólogo}

Este é o primeiro de uma série de textos que me proponho escrever sobre assuntos de espectroscopia, a pedido do actual Director do Boletim. E precisamente por isso sinto que devo explicar o que penso fazer. Dizer o como e o porquê, qual a ideia que serve de fio a isto, e mesmo em que qualidade me apresento para o fazer.

Em termos profissionais desde há muito que estou ligado a questðes de Espectroscopia. Sou investigador do INIC e faço investigação no domínio da Química Física Molecular (estudo de propriedades de moléculas orgânicas fluorescentes). No âmbito da Universidade estive até há pouco tempo ligado à cadeira de Espectroscopia.

Já passaram alguns (largos) anos desde que me formei, desde que obtive o meu doutoramento, desde que comecei a dar aulas de Espectroscopia. Foram vários os livros que li, as conversas que tive, as aulas que orientei. De tudo isso recolhi experiência, amadureci ideias. Considero que chega uma altura da vida em que tudo isso, amalgamado, dá uma espécie de visão nova das coisas.

Por outro lado essa nova visão é como que um transbordar de um copo cheio. E surge acompanhada de um vivo desejo de comunicação. É esta a primeira ideia deste texto. Comunicar. Entrar em contacto.

Mas entrar em contacto com quem? Quando telefonamos a alguém "escolhemos» o interlocutor. Uma conferência destina-se normalmente a um público determinado. Uma aula é dada a um dado grupo de alunos, que se sabe de onde vem e para onde vai. E aqui surge o pedido do Director do Boletim. O. pedido de que eu escrevesse um texto essencialmente dirigido a professores do Ensino Secundário. Não é que eles sejam uma «raça» à parte. Mas é um público qualificado.

$\mathrm{O}$ assunto é, obviamente, a Espectroscopia. O motivo é a necessidade de comunicação. Falta falar no método. Proponho-me escrever, para já, uma série de três artigos sobre Espectroscopia.

No primeiro darei uma ideia sobre o que penso da Espectroscopia. No segundo tratarei das formas habituais da Espectroscopia. Será evidentemente o texto mais "clássico». No terceiro artigo escreverei sobre formas novas e novas correntes de Espectroscopia. Uma espécie de generalização. Não esperem grandes tiradas. nem muitas formulas nem muitos gráficos. Para isso há muitos e bons textos. E um espaço próprio. Eu sei que infelizmente falta um bom livro especializado em português. Talvez um dia me abalance a fazê-lo. Mas não é aqui. Gostava que estes textos fossem uma espécie de conversa.

Ora uma conversa não é um monólogo. É uma comunicação. Entrecruzada. A palavra conversa é da família de conversação. Mudança. Depois de uma conversa já não somos, já não devemos ser, os mesmos.

Para conseguir esta conversa eu proponho o seguinte. Proponho que me escrevam. O tal "público» a quem me dirijo. Será que isto que eu vou escrever resulta? Será que eu consigo a tal comunicação que pretendo? Que me escrevam pois. Dizendo o que pensam sobre a Espectroscopia, que problemas têm ao expor aos vossos alunos as matérias relacionadas com a Espectroscopia. Qual a vossa visão sobre a Espectroscopia.

Esses elementos que eu espero receber serão assim a resposta à primeira parte da nossa conversa. E numa fase seguinte, depois de ter lido esses vossos dados, eu escreverei outros três textos, que serão por assim dizer uma nova versão dos primeiros. Enriquecido com as vossas ideias. Com a minha resposta, a minha achega à nova fase. Uma segunda demão numa pintura.

E para terminar, escreverei um texto final constituindo um fechar de ciclo, com as conclusðes. Conclusð̄es sobre a validade da experiência mas acima de tudo com os resultados da experiência.

Devo dizer que eu não tenho contacto quase nenhum com os problemas que possa haver nas aulas de Espectroscopia ao nível do Ensino Secundário. Tenho comigo alguns livros. Há coisas de que gosto, outras de que não gosto. Há inclusivamente algumas com as quais não concordo.

Mas o que me interessa aqui sobretudo é o diálogo, a conversa, a comunicação. E por isso é importante a «resposta» a esta experiência. A vossa resposta. Se a não tiver não será conversa. Não será um transbordar de um copo, uma comunicação, mas um mero despejo. Estão definidas as coordenadas. Os géneros alimentícios foram comprados. Estão sobre a mesa. Agora é preciso preparar a refeição.

\section{O que é a Espectroscopia?}

Propuz uma conversa sobre a Espectroscopia. mas o que é a Espectroscopia? Nestas coisas, um bom método é ver o que é que o nome quer dizer. No saber antigo, dar o nome a uma coisa ou um ser é adquirir uma certa posse sobre essa entidade. É mesmo um dado bíblico. Deus fez os animais, diz a Bíblia, e disse ao homem que lhes desse o nome o que significaria que tomava posse sobre eles. A ideia de haver um nome de família é outro sintoma de que o nome é importante.

\footnotetext{
a Investigador principal do INIC.
} 
Pois bem. Espectroscopia tem a sua origem no grego e significa o estudo dos espectros. Mas que espectros? Fantasmas? Até certo ponto, isso até é verdade. Mas cuidado. É que espectro significa imagem.

A Espectroscopia é então o estudo de imagens. Mas que imagens? E imagens de quê? Eu quase diria: de tudo o que é coisa, ou ser, ou ideia. O problema pode e deve pôr-se, com toda a generalidade. Só assim teremos uma visão enriquecida.

Talvez se compreenda agora melhor o que eu disse atrás sobre a visão que eu tinha da espectroscopia e sobre $o$ interesse que eu tenho nesta experiência.

O homem tem sede de conhecimento. A frase é habitual. E para aumentar o seu conhecimento normalmente ele «interroga», pesquisa, procura. Admitamos que eu encontro um amigo e que pelo seu ar ele me parece triste. E eu pergunto-lhe o que é que ele tem. Ele responde. Eu fico com uma ideia, construo uma «imagem» do estado em que ele se encontra. Pois bem, com isto eu realizei uma observação espectroscópica.

Se eu acordo mal disposto tento pensar, ou já sei, as razões da minha má disposição. Também ai eu construo uma imagem, também eu aqui fiz uma observação, uma operação espectroscópica.

Suponhamos que eu tenho comigo um sintonizador, uma telefonia. Rodo um botão. Para dadas posiçðes há silêncio, para outras músicas várias, para outras palavras. Música ligeira, música clássica, um discurso e uma peça de teatro. Com o rodar do botão fiz uma observação espectroscópica. Fiquei com uma imagem do estado das ondas que "por aí andam» pela sala.

Reparem que aqui há um elemento que é novo. Eu precisei dum aparelho para me fornecer esses elementos. É que felizmente o meu sistema sensorial não está habilitado a fornecer-me directamente essa informação. E felizmente, digo eu, como é óbvio. Já imaginaram o que seria se nós ouvíssemos todas as emissð̋es radiofonicas que poluem os ares? Talvez um dia se venha a descobrir que afinal essas ondas têm efeitos perniciosos. Pelo menos já hoje em dia se sabe que os infrasons têm efeitos perniciosos, e que o mesmo sucede às ondas de radar, por um lado, aos raios $\mathrm{X}$ por outro. Mas voltemos ao nosso assunto. Com o sintonizador eu fiz a observação espectroscópica do estado das "ondas de rádio" que estavam na sala. Tal como eu observo os móveis da sala. E reparem que também aí eu uso um sintonizador. Simplesmente esse está «incorporado" em mim. São os meus olhos. Eu vejo os móveis da sala. Movo os olhos, da esquerda para a direita, de cima para baixo, tal como rodo o botão. E vejo os livros, cada livro, as cadeiras, o candeeiro, a televisão. Como ao rodar do botão.

É a mesma coisa. Melhor, é quase a mesma coisa. Há aqui, repare-se, alguns elementos diferentes. Um é o facto que eu já referi de aqui o sintonizador já estar incorporado em mim. Se eu fosse cego não via. Mas há outra diferença, e grande. Os meus olhos são sensíveis (isto é, eu vejo), à chamada informação visível, à radiação da zona do visivel que vem dos objectos.

Mas os objectos não emitem essa radiação. Assim é que se a sala estiver às escuras eu não vejo os objectos. Preciso de luz. Uma teoria antiga sobre a visão explicava o fenomeno dizendo que os olhos emitiam pequenos corpúsculos que «batiam» nos objectos e recolhiam aos olhos trazendo-nos a impressão nova. $\mathrm{O}$ que é certo é que eu preciso de luz para ver.

Ora em que é que o fenómeno consiste? É como quem faz uma pergunta. Eu ilumino a sala, a luz bate no objecto. Ele reflecte a luz, e como é sabido, nem mesmo a reflecte toda e no caso geral até nem se deve dizer reflectir. Isto porque a luz que bate no objecto é «difundida», isto é, vai em todas as direcçð̄es. Eu podia fazer isto numa sala às escuras com uma lanterna de bolso que tem um feixe de luz que aponta. E tal como quem roda um botão, eu apontaria o feixe de luz da laterna para a esquerda, para a direita, para cima, para baixo.

Há aqui um elemento que parece novo. Eu usei um feixe de luz. Isto é como quem faz uma pergunta. Eu pergunto a uma pessoa o que é que se passa com ela. $\mathrm{E}$ ela responde. Com isso eu construo uma imagem. Faço uma observação espectroscópica. Quando uso a lanterna, eu tenho a sala iluminada.

Podemos neste momento ir um pouco mais longe e perguntar com bom senso, a nós próprios, a pergunta essencial deste texto e desta secção: o que é isso de espectroscopia?

Permitam-me no entanto fazer aqui um parêntesis para dizer que talvez quem esteja a ler estas linhas comece a perceber o "método" que eu me propus usar para a conversa. Há tantas coisas de interesse a dizer sobre Espectroscopia. No fundo, no fundo, há tanta coisa de interesse por esse mundo que nós não sabemos descobrir... E por isso não sabemos comunicar. Por isso só sabemos ser agressivos. Mas isso é outra conversa. Voltemos ao assunto da Espectroscopia.

Se eu fizer incidir o feixe da lanterna ou, na sala iluminada olhar para a lombada de um livro na estante eu quando muito vejo o título do livro, e a cor da lombada. Não vejo o que está dentro evidentemente. Se eu perguntar a um amigo o que é que ele tem e ele não responde eu fico sem saber o que é que ele tem. Fico apenas a saber, porque vejo, o seu ar exterior. A «lombada».

Isto serve para mostrar que dispor de luz, ou fazer perguntas, não chega. O "objecto» a quem se pergunta tem que responder. Como o livro fechado. Não se diz o mesmo de uma pessoa? Que é fechada, que se fechou.

Precisamos de saber perguntar. O meio, o objecto, que usamos para perguntar tem que ser adequado. Como tem que ser adequado o "objecto" a quem se pergunta. Não é costume telefonar a um amigo, advogado, perguntando qual o remédio que se deve tomar para uma doença qualquer (a não ser que saiba que ele tem ou teve esse conhecimento, por estar informado, isto é, por ter essa forma).

Eu escrevi há pouco que ao ver um objecto via a sua forma, e via, normalmente a sua cor. E como todos podem prever, na minha sala eu tenho objectos de várias cores. O que é esta questão de cor? A explicação vem na sequência do que foi escrito. $\mathrm{O}$ objecto dá-me uma certa informação sobre o seu interior. Como é sabido há uma parte de luz que ilumina o objecto que é "absorvida», e uma parte que é difundida. A luz que incide tem várias "cores» e o que nós vemos e provém do objecto é por assim dizer a resposta do objecto. É o que ele quis dizer de si, a medida do grau em que ele se abriu ou se fechou.

Chegados a este ponto podemos tentar fazer um balanço e ver se já se pode responder à pergunta. O que é isso de Espectroscopia?

A Espectroscopia é o estudo dos espectros, Com uma análise, uma operação espectroscópica, nós construimos, para nosso conhecimento, uma imagem de um objecto, de um ser, dos outros, ou de nós. De uma 
molécula, até. Para realizar uma operação espectroscópica não precisamos, evidentemente, de ter acesso ao objecto. Ele tem que estar disponível. No caso de uma pessoa às vezes é mais difícil. Há quem diga que para um negócio e mesmo para a política, um bom almoço é um bom método. Noutros casos e nesta sociedade, às vezes o dinheiro, dado com luvas (ou em luvas), para não deixar impressðes digitais.

Mas precisamos do objecto. E não só! Precisamos de um detector que nos traduza a informação que o objecto nos dá. Isto exige que se saiba «interpretar» a informação. De que serve o livro de instruçōes em Japonês? (para mim, pelo menos).

Além do detector precisamos de um outro elemento. Eu chamar-lhe-ia o perguntar. O elemento que "atira» uma pergunta. A lâmpada, a luz, a minha voz a fazer a pergunta. Essa pergunta tem que ser adequada, ao objecto que tem que estar disponivel, aberto, à pergunta, isto é, compreendê-la, e querer ou poder, responder. Tenho que usar uma linguagem adequada. Não serve de nada fazer no Japão, a pergunta do «quanto custa» em português.

Talvez agora já se tenha a resposta à pergunta inicial. $\mathrm{O}$ que é isso de Espectroscopia?

\section{O que nos dá a Espectroscopia}

Um primeiro ponto é uma espécie de verdade do Amigo banana. A resposta é em princípio a resposta a uma pergunta. $\mathrm{E}$ assim a informação que recebemos é a que pedimos. Pelo menos é assim que deverá suceder num mundo ajuizado. É isso que nós esperamos a todo o momento. As vezes as coisas saem trocadas. Como se costuma dizer, às vezes temos a resposta que merecemos e não a resposta que queremos. Muitas vezes temos a resposta que é a verdadeira e não a que pensámos que íamos receber. Sucede muitas vezes isso com um computador, como é sabido.

Num estudo normal de espectroscopia as coisas são geralmente mais normais. Normalmente nós «perguntamos» a uma molécula uma determinada informação sobre a propriedade. Para isso usamos uma «pergunta» adequada. Para facilitar as coisas normalmente esse "perguntar» é acompanhado de um tradutor de resposta. E o chamado detector. $\mathrm{O}$ equivalente à telefonia.

É claro que se o que perguntamos é para aumentar os nossos conhecimentos, o que interessa é não perder tempo. Fazer a pergunta adequada, ao objecto adequado e tendo a certeza, ou quase, que sabemos interpretar a informação (o que não quer dizer que saibamos "perceber»).

Temos assim que «analisar» a resposta ou respostas. Essa análise que nos vai dar a ideia, a imagem das propriedades do objecto, exige normalmente uma comparação de dados. E para isso é evidentemente útil ter um registo. Daí que muitas vezes a informação se guarde sob a forma gráfica, ou de um gráfico, ou de uma tabela.

Por economia de linguagem a esse gráfico, normalmente, chama-se espectro. Para quem o sabe interpretar, na realidade, esse gráfico dá a imagem do que são as propriedades do objecto. E então é na verdade o espectro. A variação da intensidade de uma emissão. Uma distribuição. O resultado de uma sondagem.

Não resisto a apontar um caso curioso e hoje em dia frequente. Julgo no entanto que para muitos a sua origem é desconhecida. Suponhamos que se quer uma informação sobre um grupo de candidatos a um lugar. Fazem-se entrevistas, testes. E suponhamos que os registos dos resultados se apresentam do seguinte modo. Horizontalmente marcam-se, em várias linhas as quantidades possíveis. E à frente o seu grau, assinalando com uma cruz a coluna correspondente: regular, mediocre, bom, optimo. Unindo as várias cruzes tem-se uma linha quebrada. Como se fosse uma cara num desenho cubista: um nariz, um queixo mais ou menos saliente, o encovado dos olhos. Âs vezes não situados no lugar conveniente mas todos nós já vimos isso em pintura. De qualquer modo, usando um pouco de imaginação chamou-se a isso o perfil do candidato. E claro está, havia o "perfil ideal». Hoje em dia é frase corrente, objecto de pesquisa, e comunicação à imprensa. $\mathrm{O}$ que interessa para aqui, no entanto, é que como resultado da análise espectroscópica nós obtemos normalmente o registo das propriedades do objecto, registo a que chamamos o espectro.

E está fechado o ciclo - Perguntou-se, usando o processo mais adequado. Colocou-se, ou usou-se, o objecto na posição (ou disposição) adequada. E recebeu-se a informação pretendida. Com isto ficamos a saber qualquer coisa mais sobre o objecto.

Nas suas linhas gerais, é isto que a Espectroscopia nos dá. As propriedades, algumas, pelo menos, de um objecto. Objecto aqui tomado no seu sentido mais geral, como o provam a variedade dos exemplos escolhidos.

Mas será só isto? Já não era mau. Já que chegou para dizer que quase tudo é espectroscopia. Mas pelo menos suficiente para dizer uma frase que eu gosto muito de repetir: a fala é a Espectroscopia do espirito. Mas. Mas não é só isto, o que a Espectroscopia nos dá. Quando num processo temos vários elementos sucede geralmente que se conhecermos as regras do processo podemos ficar a saber qualquer coisa sobre um dos elementos desde o momento que conheçamos os outros. Veja-se por exemplo a relação simples

$$
\mathrm{A}+\mathrm{B}+\mathrm{C}=1
$$

em que A,B,C podem ter quaisquer valores numéricos. Como é b́bvio, se eu souber os valores de duas destas grandezas posso calcular a terceira.

No conjunto global de uma observação espectroscópica há uma fonte (o tal perguntador), o objecto e o detector. Pois bem, se eu conhecer as propriedades do objecto e dominar as características do detector, posso estudar as propriedades da fonte. Ou dito de outro modo, posso estudar várias fontes, de modo a poder eventualmente escolher a fonte adequada para qualquer trabalho que surja. Se em contrapartida eu dominar as propriedades da fonte e do detector, posso estudar vários objectos. Este é na realidade o campo que até aqui tem sido o campo por excelência da espectroscopia, quando o objecto é o átomo ou a molécula. Finalmente se eu conhecer as propriedades da fonte e do objecto posso estudar o detector.

Mas não se esgotam aqui as possibilidades da Espectroscopia. E refiro-me aqui especialmente ao que é costume chamar métodos de análise. Já que estamos aqui a "conversar» em linhas gerais sobre o que é na generalidade a Espectroscopia cabe aqui referi-los.

Suponhamos que ao estudar, por operaçð̄es espectroscópicas, vários objectos eu fico a conhecer as características de um conjunto de objectos. Então se eu tiver um objecto que é uma "mistura» desses objectos, eu posso fazer o que se chama uma operação de análise 
qualitativa. Isso é equivalente a determinar quantos e quais dos objectos primários se encontram no objecto complexo, no objecto mistura.

Mas muitas vezes podemos mesmo ir mais longe. Ao medir o resultado da interacção entre o que é emitido pelo detector e o objecto o detector regista uma certa «intensidade». Pois bem eu posso usar o valor dessa intensidade para saber quanto é que existe em termos correntes, peso, volume, concentração, desse objecto numa mistura. Realizo assim uma análise quantitativa. Propus-me num primeiro escrito, facilitar um discussão sobre o tema "o que é isto de espectroscopia". Num texto dirigido a um público concreto, e como primeira parte de um trabalho em que o diálogo seria um ponto importante.

Tal como disse anteriormente, mais dois textos se seguirão. Depois, como disse também, logo se verá. para já sentir-me-ia satisfeito se alguém que lesse isto pudesse conversar com um amigo ou um aluno e fosse, finalmente capaz, de explicar, em termos correntes mas correctos, o que é isso da Espectroscopia.

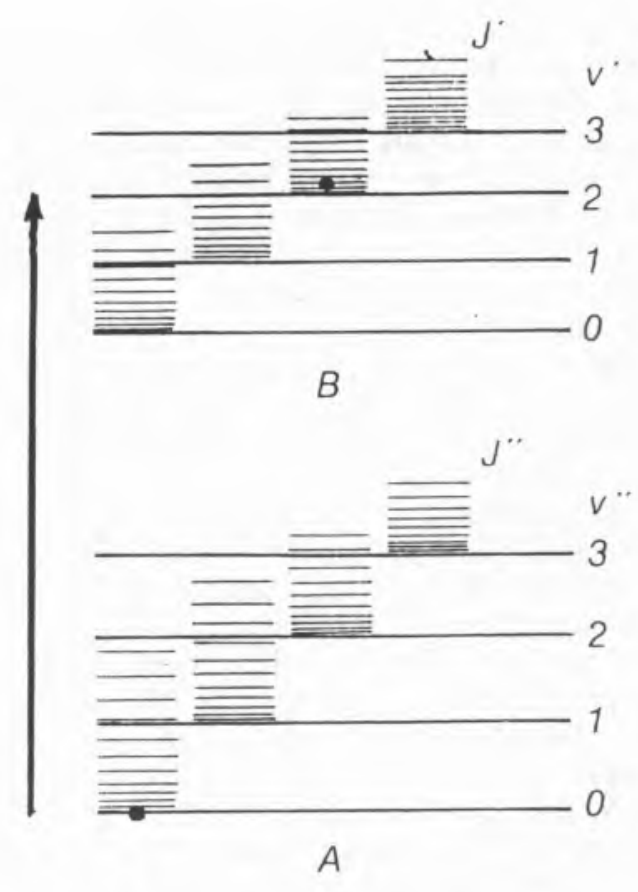

dizendo que $v$ é o número quântico vibracional, $J$ o número quântico rotacional e que no exemplo considerado a molécula passa do estado electrónico 1 , nível vibracional zero e nível rotacional zero para o estado electrónico 2, nível vibracional $v=2$ e nível rotacional $J=2$.»

Creio, como disse atrás que este texto se poderia encontrar num livro corrente sobre espectroscopia. Não o copiei de nenhum sítio mas escrevi-o aqui directamente.

Mas não me esqueço do público a quem me dirijo essencialmente e do objectivo a que me propus. Algumas reflexð̃es para leitura de professores do ensino secundário. E o que eu pergunto a mim mesmo é se bem escalpelizado este texto se percebe.

Interessa-me aqui, à boa maneira Socrática «espicaçar» os espíritos. Levá-los a pensar, e perder o hábito de despejar. Sobretudo o que é preciso é abandonar a ideia da aula magistral, tipo carregar no botão, sai formula e quadro cheio. É preciso saber explicar, criar no aluno a convicção que o conhecimento humano tem uma lógica, que o que sabemos foi evoluindo na medida em que os chamados criadores de ideias usaram as ideias já criadas e sobre elas construiram coisas novas. Mesmo ao corrigir desvios, caso em que parece que as ideias já feitas foram deitadas abaixo, e foram-no realmente, o que é certo é que a ideia «errada» teve a sua importância e a sua época histórica. isto levava-nos muito longe e não interessa para aqui.

E começo por algumas perguntas.

O que é que na verdade significa "decompôr» a energia em electrónica, vibracional e rotacional? $O$ fotão que a molécula absorve é uma entidade única, indivisível, não tem cabeça, tronco e membros. Não se pode dizer que ao absorver a energia ele se divide em três bocados. É assim intrinsecamente errado escrever

$$
\nu=\nu_{\mathrm{el}}+\nu_{\text {vib }}+\nu_{\text {rot }}
$$

Quem lê estas linhas já terá alguma vez usado esta expressão que está na verdade a subentender que se "decompð̃e» o fotão absorvido? Na realidade, a molécula absorve a energia como um todo. Daí a detecção, num espectro, de uma risca de absorção. 
Pois bem, a molécula vai, por assim dizer, administrar essa energia, como quem recebe uma mesada e a gasta em várias coisas. Repare-se contudo, na subtileza. A molécula recebe a energia na sua totalidade, e depois, como quem mete em vários envelopes, ou gavetas, ou niveis de energia, arruma-a.

Ora quando se verifica experimentalmente (e se confirma por cálculo de modelos, como é o caso) que o período das rotaçôes moleculares é da ordem de $10^{-12}$ seg., que o período das vibraçðes dos átomos nas moléculas é de $10^{-14} \mathrm{seg}$. e que o período do movimento dos electrőes é da ordem dos $10^{-13} \mathrm{seg}$. isso significa, por exemplo, que se podem dar cerca de 1000 vibraçðes considerando a molécula por assim dizer parada, do ponto de vista rotacional. Sendo possivel «quantificar» o movimento de rotação, isto é, tratá-lo matematicamente por um modelo quântico e comprovar experimentalmente que esse modelo é adequado quando se estudam espectros de rotação puros, isto é onde só o nivel de rotação é alterado. Torna-se então legítimo separar a energia de vibração da energia de rotação e dizer que "para um dado nível de vibração se podem considerar vários níveis de rotação". E do mesmo modo para os niveis electrónicos.

Assim, é válida a equação que envolve a constante de Planck $h$, desde que se admita que ela é simbólica. O valor $\nu_{\mathrm{el}}$ é a frequência do fotão que seria absorvido numa transição electrónica pura; o valor $\nu_{\text {vib }}$ é a frequência do fotão que seria absorvido numa transição vibracional pura; o valor $\nu_{\text {rot }}$ é a frequência do fotão que seria absorvido num espectro de rotação puro.

E agora, só agora, é que numa aula ou discussão será legitimo começar a escrever algumas fórmulas. Rotor rígido, energia de rotação, constantes de rotação. Oscilador harmónico, correcção anarmónica, constantes de vibração. Transiç̧̋es electrónicas puras, estados $\pi, \pi^{*}, \sigma, \sigma^{*}, \mathrm{n}$.

Depois começam as complicaçôes. E não haveria melhor prova de que em tudo isto há aproximaçőes. Os modelos actualmente usados são adequados, mas as correcçðes introduzidas mostram bem que a tal forma de decomposição de energia deixa muito a desejar.

Assim, nos espectros de rotação aparecem constantes de rotação que dependem do estado de vibração. Nos espectros de vibração são as correcç̄es de distorção centrífuga (obviamente relacionadas com a rotação) que vão ter importância. E se numa primeira aproximação nós podemos considerar as vibraçōes separadamente, isso é graças à introdução das chamadas vibraçত̋es fundamentais que são em si um complexo de vibraçðes. Passe a ironia da frase, mas o que sucede é que para termos a regalia de esquecer a existência de «termos cruzados» envolvendo várias vibraçðes fundamentais, temos que considerar a molécula a vibrar como um todo.

Muito haveria para dizer. Mas o que pretendi nestas linhas foi dar a ideia (minha aliás) de respeito pelo rigor, pelo modelo. É preciso ir ao fundo da questão, em cada aula, em cada conversa. E termino esta secção com um exemplo que me parece sugestivo. $\mathrm{O}$ espectro de vibração da água. Há três vibraçð̃es fundamentais, que não são simples. $\mathrm{E}$ as vibraçð̋es que se observam são as vibraçס̃es fundamentais, os harmónicos e as suas combinaçðes. Não há dúvida que a molécula «se arranja como pode para arrumar a energia que recebe» e que revela muita imaginação nisso. Está-se bem longe do modelo puro, que aliás continua bem presente na base de tudo o que se discute. Mas não é isso que se passa connosco nesta nossa sociedade? Sondagens, estatísticas, tudo certo. Depois, correç̧ð̃es, acertos. Depois... o voto!

\section{Espectros Atómicos}

Num texto sobre problemas de espectroscopia nunca falta um capítulo sobre espectros atómicos. A proposito fala-se em átomos e há normalmente um parágrafo ou outro dedicado à evolução dos modelos atómicos. Rutherford, Bohr, Sommerfeld, a mecânica quântica depois. Contudo, nos últimos textos que eu li começo a vislumbrar uma certa confusão.

É costume dizer que traduzir é trair. E que quem conta um conto acrescenta um ponto. Conta-se a história de um rei que queria saber por que razão, apesar dos impostos lançados sobre os habitantes do reino, os cofres do Estado estavam vazios. E um conselheiro do rei pediu ao rei para se sujeitar a uma experiência. Mandou reunir o Conselho de Estado e pediu ao Rei para colocar os Conselheiros em fila, ficando o Rei numa ponta. Ao Conselheiro colocado no outro extremo deu uma mão-cheia de areia e disse aos Conselheiros que fossem passando a areia de mão em mão, até chegar ao Rei. É claro que quando chegou ao Rei já não havia senão alguns grãos de areia.

Tenho impressão que com os modelos atómicos quase se passa uma coisa semelhante. À força de contar a história ela foi perdendo o sentido. Estereotipou-se, solidificou, esquematizou-se.

E contudo ela é fundamental. Fundamental até porque ela condicionou fortemente a evolução do pensamento humano. A evolução dos modelos atómicos está na base do aparecimento da Mecânica Quântica. E a mecânica quântica introduziu uma tal revolução no pensamento humano que nada do que se passou depois a pode igualar.

Dentro do espírito com que são escritas estas linhas deixem-me pois expor algumas ideias sobre isto.

Estava-se em 1912. Em Manchester, para onde tinha ido parar, vindo da Austrália onde tinha trabalhado com substâncias radioactivas, estava Rutherford. Rutherford que já em Manchester tinha desenvolvido um modelo atómico. Como é sabido, Rutherford tinha bombardeado um alvo muito puro de ouro (escolhido pela simples razão de que é possível conseguir folhas muito finas) com partículas $\alpha$ e tinha verificado que algumas partículas $\alpha$ sofrem deflexðes apreciáveis. Isso só poderá ser explicado se se admitir a existência de pequenos corpúsculos de electricidade positiva concentrados num espaço muito pequeno. Rutherford chamou a esses corpúsculos núcleos e idealizou um modelo atómico, que foi chamado planetário porque era semelhante ao sistema dos planetas no sistema solar. Sabia-se já nesse momento que nos átomos havia electrôes, partículas de carga negativa. Pois bem, no entender de Rutherford os átomos eram constituídos por electrôs movendo-se em torno do núcleo com um movimento regido pela lei de Coulomb de atracção de cargas eléctricas.

Seja-me permitido aqui um parêntesis mas que está dentro do espírito que estas linhas pretendem ter. Faz-me impressão, sempre me fez, a imprecisão linguística. A palavra tem um certo significado. E atrás da palavra vai sempre uma mensagem, não é o acordo ortográfico que interessa, o que interessa e interessa aqui fortemente. Lembro-me de que ouvi um jornalista dizer que $" \mathrm{O}$ Sr. Ministro veio aqui inaugurar algumas 
carências...). Ora é costume, tristemente costume, dizer que no Átomo de Rutherford os electrōes gravitam em torno dos núcleos. Errado, meus amigos. Isso significaria que os electrôes se movem em torno dos núcleos sujeitos à lei da gravidade. Ora tenhamos um bocadinho de bom senso. Basta um pequeno cálculo, usar a massa do electrão e a massa do um núcleo para verificar que a força de gravidade que entre eles se exerce é completamente desprezável face à interacção devida à carga eléctrica. Portanto o electrão não gravita em torno do núcleo. Quando muito o electrão coulombiza em torno do núcleo. E mesmo isso, quanto a mim, terá que ser visto com cuidado.

Mas voltemos ao modelo atómico de Rutherford. Ai as coisas são diferentes. Sujeitos à lei de Coulomb, os electrōes movem-se, como pequenos planetas, em torno de um sol, que é o núcleo. E as órbitas? São circulares, elipticas? Acontece que de acordo com uma lei de Maxwell, uma carga eléctrica com movimento acelerado radia energia. ora se o electrão radia energia, verdade do Sr. de La Palisse, perde energia. Mas se perde energia, o raio da sua órbita em torno do núcleo tem de diminuir. Então a órbita não pode ser circular. É uma espiral. E fatalmente o electrão cai, choca com o núcleo.

Em princípio isto pode não ser causa de alarme, mas se fizermos os cálculos a coisa complica-se pois pode verificar-se que o raio da trajectória do electrão atinge os $10^{-12} \mathrm{~cm}$, considerados o diâmetro dos núcleos, em tempos da ordem dos nanosegundos e a conclusão é assustadora. Se os átomos são como Rutherford propôs, eles são instáveis. Duram $10^{-9}$ segundos! Ora toda a gente sabe que assim não é. Os átomos são estáveis. Além disso, de acordo com a teoria de Maxwell a radiação de energia por parte dos electrōes deve ser a de energia com uma frequência igual à do seu movimento. Ora no seu movimento espiraloide a frequência varia continuamente. Então a radiação emitida pelos átomos deveria ser a de um espectro contínuo. Contudo os dados experimentais mostravam que um conjunto de átomos excitados radiava um espectro descontínuo, de riscas, que se sabe agrupar em séries perfeitamente definidas.

Em 1912 em Manchester, era esse o impasse. O átomo "planetário» de Rutherford explicava as experiências das partículas $\alpha$. As equaçőes de Klein e Nashima que estudavam a intensidade de um feixe de partículas, tinham sido verificadas. Fosse qual fosse a explicação o átomo de Rutherford não pode ser esquecido nem atirado para o cesto dos papéis.

Chega-se a 1913. Tinha vindo trabalhar com Rutherford um jovem físico dinamarquês, Niels Bohr. Baseado nos trabalhos de Planck sobre a teoria do corpo negro, e que já eram conhecidos desde 1900, e sobre os estudos de Einstein (1908) do efeito fotoeléctrico, Bohr «resolve» que o melhor processo de assegurar que o átomo de Rutherford seja estável é postular que é estável. E vai mais longe. Afirma que as órbitas em que o movimento angular é igual a um múltiplo da constante de Planck dividido por $2 \pi$ não perdem energia.

Assim as órbitas em que

$$
\mathrm{mvl}=\mathrm{n} \frac{\mathrm{h}}{2 \pi}
$$

não radiavam energia, eram estáveis. Mas se o electrão passasse de uma órbita caracterizada por um dado $\mathrm{n}$ para outro de raio menor com um $n$ menor, radiava energia com uma emissão de um fotão (hipótese de
Einstein) de energia $\mathrm{h} \nu$, de acordo com as ideias de Planck (o tal postulado era revolucionário, é certo, mas de acordo com as ideias revolucionárias já em vigor na época). O espanto da história é que nesta base se explicavam as conhecidas leis empíricas dos espectros dos átomos, de um modo tão perfeito que o problema podia considerar-se resolvido.

Temos aqui um belo exemplo do que pode ser aqui a interacção entre o teórico e o experimental. É para mim evidente qu existe a chamada verdade dos factos. $\mathrm{O}$ universo físico existe e é de determinada maneira. Ao longo dos tempos os homens foram tirando o véu que tapava os conhecimentos (chama-se a isso descobrir). E é curioso verificar a intuição de um jovem, Bohr, resolvendo, graças à sua intuição, o problema que preocupava os grandes mestres.

Controvérsia aqui, controvérsia acolá, o modelo de Bohr soube vencer.

E quando parecia sossobrar recebeu novo alento devido à contribuição de De Broglie. Discutia-se o dualismo onda-corpúsculo. Sabia-se da existência de ondas electromagnéticas mas que os fotðes se comportavam como corpúsculos. Os electrōes comportavam-se como corpúsculos. porque não, por uma questão de harmonia, admitir que em determinadas circunstâncias eles se comportavam numa experiência, como uma onda? Se assim fosse o seu comprimento de onda deveria ser dado tal como para os fotð̌es, pela razão entre a constante de Planck e quantidade de movimento

$$
\lambda=\frac{\mathrm{h}}{\mathrm{mv}}
$$

Pois bem, o logico seria admitir agora que para que as orbitas admitidas por Bohr fossem «estacionárias», não radiassem energia, era necessário admitir, dizia eu, que elas se "fechassem» isto é, que o comprimento de onde fosse um sumúltiplo do perímetro

$$
2 \pi \mathrm{r}=\mathrm{n} \lambda
$$

Então

$$
2 \pi \mathrm{r}=\mathrm{n} \frac{\mathrm{h}}{\mathrm{mv}}
$$

e assim

$$
\mathrm{mvr}=\mathrm{n} \frac{\mathrm{h}}{2 \pi}
$$

Encontramos o postulado de Bohr! Mais do que isso, justificamos o postulado. Mais ainda, levanta-se novos pontos do véu. O mundo dos átomos pode ser descrito com base numa teoria ondulatoria. Estava aberta a porta da Mecânica Quântica.

\section{Spin e efeitos magnéticos}

Interacção entre a teoria e a experiência. Encontro entre cientistas, técnicos e experimentalistas, numa sã conferência que se perdeu mas que é necessário reencontrar, provocam uma funda reformulação de conhecimentos. Ramos que pareciam divergentes, como a Mecânica das matrizes e a Mecânica Ondulatória são unificados pelos trabalhos desse génio que foi Dirac. Dirac a quem se deve, entre outras contribuiçōes, o estudo relativístico das equaçōes de onda, através das quais se demonstra a existência de um fenómeno não existente, melhor, não patente na mecânica clássica - o movimento intrínseco das partículas, que tinha sido introduzido como hipótese por Pauli - o spin. 
Eis aqui um outro assunto que merece refexão. $\mathrm{O}$ spin. Estamos no fundo de um saco. Fenómeno radiativo só determinável no âmbito de teorias complicadas com velocidades electrónicas próximas das da luz. Hipótese de spin, essencialmente introduzida para explicar o chamado efeito de Zeeman anómalo.

$O$ efeito de Zeeman foi descoberto por Zeeman e diz respeito ao desdobramento de riscas de um espectro quando sobre a fonte que emite o espectro se faz actuar um campo magnético. Pois bem, o que a teoria previa era que uma dada risca se desdobrasse em três. Isso verifica-se, é certo, mas em poucos casos. O que acontecia era verificar-se o aparecimento de um conjunto de riscas, com número imprevisível. Chamou-se a esse efeito o efeito de Zeeman anómalo. Mas o que é curioso é que no fundo o efeito de Zeeman anómalo é que é perfeitamente normal e o efeito de Zeeman normal é que é fora da normalidade.

Os raciocínios que estão na base do efeito de Zeeman são os seguintes. $\mathrm{O}$ momento angular de rotação pressupð̃e um movimento do electrão. Assim sendo é a criação dum campo magnético, e a possibilidade de definição dum momento magnético. Nessa altura ạ energia varia de acordo com as leis de quantificação habituais, haverá tantos níveis de energia diferentes quantas forem as possibilidades de projecção do vector momento angular relativamente a um eixo de referência. Esse número de posiçð̄es implica a possibilidade de um "movimento" do momento angular numa superficie conica.

É este outro ponto que merece uma reflexão. A cada posição do momento angular corresponde um plano perpendicular onde se situa a órbita do electrão. O que é diferente de caso para caso é a posição do plano. O resto vem por acréscimo. Mas o que acontece é que a descrição do fenómeno pode ser feita "segundo" o tal movimento de percurso do movimento angular.

$\mathrm{E}$ tantas quantas forem as possibilidades desse movimento sobre a superfície cónica tantas serão as projecçð̄es possíveis do momento angular. Mostra a Mecânica Quântica que se for $l o$ valor do número quântico do momento angular que quantifica o módulo do momento angular de acordo com a espressão habitual

$$
|l|=\sqrt{\mathrm{L}(\mathrm{L}+1)} \frac{\mathrm{n}}{2 \pi}
$$

o número de projecçð̃es possíveis de $l$ sobre o eixo dos zz é $2 l+1$ e que, se se fizer coincidir o campo magnético exterior com a direcção do eixo dos zz o acréscimo de energia do electrão na órbita é

$$
\Delta \mathrm{E}=\mathrm{B}_{l} \mathrm{HM}_{l}
$$

em que

$$
\mathrm{B}_{l} /=\frac{e h}{4 \pi \mathrm{m}_{\mathrm{e}} \mathrm{c}}
$$

é o magnetão de Bohr, $\mathrm{m}_{\mathrm{e}}$ é a massa do electrão e $\mathrm{M}_{l} \mathrm{o}$ número quântico magnético orbital que pode tomar os valores

$$
\mathrm{M}_{l}=-l,-l+1, \ldots, l-1, l
$$

Com estas simples formulas é possivel explicar o tal efeito de Zeeman normal. E surge então o spin. É como se fosse um novo momento angular que vai poder combinar-se com o momento angular orbital, criando um momento angular total cujo módulo e projecçð̄es possíveis são quantificadas de modo semelhante ao indicado acima. Um pormenor curioso é no entanto que uma vez que o spin não é propriamente um vector é de sua própria natureza que o momento magnético tenha associado um factor (o factor de Landé), de valor aproximadamente 2. Daí, como vemos, levar uma certa complexidade de análise mas daí também a possibilidade de explicar o tal efeito de Zeeman anómalo. Mas o efeito de Zeeman exige a transição entre níveis electrónicos. E que tal a exploração espectroscópica entre os níveis de spin puros? Ao fazê-lo teórica e experimentalmente surge uma das maravilhas deste século.

Espero que compreendam o que eu quero dizer já que me leram até aqui. Tenho procurado dar algumas, se bem que dispersas, ideias sobre Espectroscopia. O estudo de transiçøes entre estados de spin puros trouxe uma nova revolução ao conhecimento de átomos e moléculas.

Trata-se de ir ao mais fundo dos níveis. Quase como se tirasse um pozinho com um sopro. Se se trata de um electrão não ligado a outro por forças de spin (um electrão desemparelhado) temos as técnicas de EPR, aplicáveis a substâncias paramagnéticas, radicais, estados tripletos.

Mas a grande atenção vai para o NMR em que o spin envolvido é o do núcleo. Então no magnetão de Bohr, a massa que aparece é a do núcleo e não a do electrão. Ora os núcleos podem ter spins de vários valores, uma vez que ele é o resultado dos spins dos nucleðes que os compðem. Acontece que para o carbono é zero, para o hidrogénio é 1. Então em primeira análise o NMR para um Químico Orgânico será um meio de contagem de átomos de hidrogénio. Contudo isso não é assim, porque cada átomo de hidrogénio vai sofrer o efeito do "ambiente» dos spins dos átomos vizinhos. E vê-se assim o poder do novo instrumento de análise. De há largos anos para cá as técnicas de NMR são de utilização imprescindível para a Química Orgânica.

Nesta soma de escritos sobre espectroscopia procuramos trazer aqui qualquer coisa hoje sobre os aspectos mais clássicos. Mais ideias que factos. No próximo tentaremos alargar o leque destes aspectos.

\section{Parte III}

\section{A. Espectroscopia e Ciências Biológicas}

Esta é a terceira parte de um conjunto de textos sobre Espectroscopia que me propus escrever a pedido do actual Director do Boletim, e especialmente dirigido aos Professores do Ensino Secundário, dando-lhes conta de algumas das minhas ideias sobre a Espectroscopia. Textos que quereria que iniciassem com diálogo. Tenho esperança que alguém me escreva ou procure um outro contacto. A estes três textos outros três e um final, à guisa de conclusão, se seguirão, se esse diálogo tiver lugar ou surgir a evidência a justificá-lo. 
Escrevi estes textos com prazer mas não para ter prazer. Não tenho a mania da "missão a cumprir» embora, ao longo da vida tenha procurado vislumbrar o quinhão que me cabe na marcha da Evolução. Mas não quero escrever para me desobrigar ou só para tirar prazer nisso. Há muito boa gente que gosta de ensinar. optimo. Mas muitos há que gostam de ensinar determinadas coisas, e só essas. Já imaginaram um médico que, fosse qual fosse a doença do paciente, lhe fazia uma operação ao apêndice só porque gostava?

Nesta terceira parte, e última, desta série, gostaria, pois me parece um digno fecho, de escrever qualquer coisa menos clássica. De lançar algumas dúvidas, etc. E começa com uma reflexão.

$\mathrm{Na}$ segunda parte destes escritos foi dito que uma das técnicas mais apuradas da espectroscopia era a do NMR. Ir-se tocar no mais íntimo dos movimentos - o movimento intrínseco próprio, de retoque relativista que é o spin do núcleo. Como habitualmente o que se detecta é uma diferença de energias. Mas, tal como foi referido, no NMR o que se detecta é o diferente efeito que grupos funcionais diferentes têm sobre um átomo de hidrogénio. $\mathrm{E}$ isso inicialmente devido ao spin dos átomos vizinhos, ao efeito magnético desses átomos. Técnica requintada. Expondo alta estabilidade, campos intensos. Análise matemática sofisticada, estudos requintados. Para além de aplicaçðes que já prefiguravam os campo, onde hoje actuam, espectrocopistas do NMR desenvolveram trabalhos notáveis no domínios do estudo de reacção em Química Orgânica, estudo de grupos, isomerizaçðes, configuração espacial. Mas uma nova ideia surgiu um dia. Se os grupos funcionais desempenharem um tal papel no "sinal» de NMR que uma molécula deixava adivinhar, qual seria o efeito de sujeitar uma macromolécula, uma dessas complexas entidades do interesse dos bioquímicos e biofísicos, a técnicas de NMR? O resultado foi reconfortante. Há um sinal sui generis, denunciador e elucidador de estruturas.

De então para cá a Bioquímica e a Biofísica não se separaram mais das técnicas de NMR, tal como tinha sucedido com a Química Orgânica.

Faltava dar um novo passo. Aplicar o NMR aos proprios seres vivos.

Eram conhecidas já aplicaçð̃es de Espectroscopia aos problemas de seres vivos, no campo da Medicina. Como é óbvio um dos campos mais importantes era o das Análises Clínicas. Cada vez mais utilizadas em diagnóstico, determinação de sais, identificação de compostos e sua análise quantitativa tudo isso segue as regras da Espectroscopia Clínica.

Era também conhecida de longo tempo a técnica de raios X. Essencialmente aplicada primeiro ao tecido ósseo, viu alargado o seu campo graças a métodos sui generis. Se se pode seguir a imagem de objectos opacos (ou mais opacos) aos raios $\mathrm{X}$, então porque não «encher» os órgãos (estômago, intestino, vasos sanguíneos) com substâncias opacas e sujeitá-las depois aos raios X? E assim foram detectadas anomalias nesses orgãos, como é do conhecimento corrente.

Contudo não se pode abusar dos raios X. Em Medicina pré-natal poderiam ser (e são) úteis. O uso frequente pode provocar o cancro. Havia que procurar novas técnicas. Elas surgiram com o NMR. É para mim uma das maravilhas de aplicação da Espectroscopia a aplicação do NMR. Uma técnica que parecia ser do domínio exclusivo dos laboratórios que se dedicaram a estudos refinados de estrutura molecular veio afinal a ser um poderoso instrumento de trabalho, no domínio dos estudos sobre os seres vivos. Análise de zonas anómalas, em especial no domínio da oncologia, mas não só, preparação de intervenções cirúrgicas, estudos no domínio cerebral.

Em minha opinião foi o sucesso do NMR em Medicina que abriu caminho a novas técnicas. Baseado em efeito de som, como a Ecografia. Em efeitos de calor, em efeitos de micro-ondas.

Hoje em dia o técnico espectroscopista tem o seu lugar imprescindível junto do médico. E não me parece possível a organização de um bom Hospital sem um Departamento de Espectroscopia.

\section{Espectroscopia e Ciências Sociais}

Mas não é só no domínio das ciências biologicas que a Espectroscopia se tem vindo a desenvolver nas últimas décadas. Em minha opinião este assunto não tem sido encarado devidamente. Refiro-me concretamente às Ciências Sociais. Observam-se técnicas de recursos, soluçð̄es em cima do joelho, precárias de emergências. Deixem-me expôr algumas ideias. Técnicas de mercado por exemplo. As análises são diferentes, as estruturas mal elaboradas, incompletas e portanto de errada interpretação. Técnicas de economia. O problema é semelhante embora cada vez mais se sinta a necessidade de intervenientes nas coisas de economia terem a ajuda de métodos matemáticos.

E liga-se aqui o problema da informática. A humanidade assistiu, nos últimos anos, ao que já se chama a revolução informática. Basta ler esse livro famoso que é a Turing Machine. Quem já alguma vez teve, por gosto ou necessidade, de dialogar com um computador, deixou de ser o mesmo. Eu já li um livro dedicado a um computador.

É claro que do ponto de vista de utilização dos meios de informática ressaltam de imediato duas vantagens que só por si justificam que se fale de revolução. A compilação e a comparação de dados. Pode guardar-se em computador um enorme conjunto de dados, ocupando espaços reduzidíssimos se fôssemos compará-los a folhas de cadernos. Mas para além disso o acesso a esses dados é fácil (muito mais do que se fôssemos buscar um "dossier» a uma gaveta). Mas mais ainda o computador compara e analisa em conjunto esses dados com uma facilidade e rapidez que a sua substituição nesse trabalho só poderá ser feita com pessoal numeroso. Se juntarmos a isto a capacidade que o computador tem de efectuar cálculos também aqui com uma velocidade não conseguida pelo operador poderemos ver o que o computador traz de novo.

Mas nós estamos a considerar problemas de Espectroscopia e não de informática. Ainda por cima num texto sui generis, misto de divulgação e reflexão. Muito haverá por dizer sobre este assunto mas não cabe aqui. Onde é que cabe então o Espectroscopista? Quanto a mim, em dois pontos. Um é na pergunta feita ao nivel do programa. $\mathrm{Na}$ elaboração do programa. E outro, que é que se uma nova técnica espectroscópica, na análise dos dados compilados e fornecidos pelo computador. Pode entrar ai toda a capacidade inventiva de um espectroscopista. Pode aí toda a calma e ponderação de um bom técnico ter a sua aplicação.

Li há tempos numa revista de Espectroscopia que se o espectroscopista se não sabe reconverter, ele terá de seguir facilmente "o caminho dos dinossauros», isto é, 
desaparecer pura e simplesmente. Quanto a mim isto é um dos caminhos possíveis da reconversão. De um outro falaremos na secção seguinte.

Esta nova faceta (será mesmo nova ou um novo grau?) do espectroscopista tem uma incidência directa em Ciências Sociais. E estive aqui a pensar em Ciências de Educação e em Meios de Comunicação.

Não cabe aqui, por manifesta falta de espaço, desenvolver estes assuntos. Mas qualquer deles acaba por ter uma secção que é o estudo do modo como se devem difundir as ideias. Ora é sabido como a geração jovem actua e é receptiva à ideia transmitida por imagem. Houve tempo em que a mensagem verbal era a única possível. Mas houve tempos em que a mensagem era o ensaio, o livro, a peça de teatro. Hoje em dia é a imagem que domina. $\mathrm{O}$ cinema já era um pronúncio. Mas a televisão veio superar e ultrapassá-lo, quanto a mim. $\mathrm{E}$ a imagem inundou tudo. $\mathrm{O}$ vídeo começa a querer ser peça caseira. O Conhecimento é reduzido a tabelas, gráficos, listas, linhas.

Que campo largo se abre aos espectroscopista, habituado a lidar com espectros. Abriu-se a porta do espectro puro. Que se pode dizer, com uma certa ironia, que se está à beira da espectroscopia pura. A prová-lo está em que ela, na sua forma de graficos, começa a ser uma forma de Arte.

Ciências de Educação. Educar é conduzir. Quanto a mim é ajudar a formar um espírito capaz de fazer progredir a Evolução. Li há pouco tempo que educar é "dar uma Mensagem que não sofra constestação». Estou em completo desacordo. Quanto a mim é necessário dar ao educando os meios necessários para ele se saber comportar sozinho neste emaranhado complexo que é a Vida. Saber ensinar, isto é mostrar o sinal da Verdade mas esperar que o aluno o recolha. O Mestre deve orientar, mostrar o caminho (importante é mostrar que há um caminho). E sobretudo ensinar a caminhar sozinho.

Ciências de Comunicação. Muito se poderia escrever sobre isto. As técnicas. os objectivos. os desvios, O poder da imagem, mais uma vez.

Abrem-se hoje em dia campos nunca imaginados. Nas cassetes de vídeo constroem-se maravilhas. Os resultados artísticos são abundantes.

\section{A Espectroscopia e as Ciências Físicas e Químicas}

Guardei para o fim algumas notas sobre o domínio da Espectroscopia mais clássica. Num curso básico sobre espectroscopia, tal como referi na segunda parte destes textos, é ponto obrigatório a espectróscopia molecular, electrónica, vibracional, de rotação; a espectroscopia atómica; a espectroscopia de campos magnéticos começa a ser constante, também. Depois vêm as chamadas outras formas de espectroscopia, desde as mais "antigas» como os raios X, espectroscopia de fotoelectrðes, as mais «modernas» como a de Mossbauer.

A espectroscopia de massa também tem o seu lugar. Pode discutir-se se cabe dentro da definição de espectroscopia. Dentro do espírito com que estas linhas foram apresentadas é evidente que cabe. $\mathrm{O}$ que interessa é elaborar um espectro, uma imagem. Ora qual é o "original» da imagem que é o espectro de massa?

Recorde-se que num espectro de massa se observa um conjunto de riscas ou bandas, em que cada pico corresponde a um valor da relação entre a carga e a massa de um ião. Ião esse que é produto da excitação de uma molécula com um feixe electrónico, molécula que se fragmenta em vários iðes. É como que uma explosão. E o espectro de massa é a imagem dessa explosão, de uma espécie de fogo de artifício. Forma de espectroscopia, pois, o espectro de massa.

E deixei para o fim uma forma de espectroscopia que muitas vezes é relatada em associação com a espectroscopia de absorção eléctrónica. Trata-se da fluorescência e a sua forma associada fosforescência.

$\mathrm{Na}$ fluorescência é a luz que é emitida pela própria molécula (ou átomo) excitado que é detectada e analisada. Já não é como um absorção em que o feixe emitido por uma parte é modificado na sua composição. Quando interactua com o objecto e daí termos informaçð̄es sobre as propriedades do objecto, mais concretamente sobre os níveis de energias moleculares. Agora é a desexcitação que por ser radiativa (não confundam com radioactiva) permite o estudo de estruturas.

Normalmente é o estado electrónico singuleto excitado de mais baixa energia que é responsável pela emissão da luz, nas moléculas orgânicas. Mas outros níveis podiam intervir, em complexos de transferência de carga em exciplexos, em excímeros. Muito haveria que contar aqui.

Gostaria de realçar a importância que tem hoje a fluorescência no domínio de identificação de espécies quimicas. Daí a tão larga utilização no estudo de reacções, onde se incluem as que se dão com níveis excitados.

Atenda-se sobretudo a que um grande número de moléculas de interesse biológico são fluorescentes. Note-se que um grande número de processos de transferência de energia entre moléculas podem ser seguidas por técnicas de fluorescência e que um número cada vez maior de reacçōes que se dão ao nível da célula podem ser estudadas por técnicas de fluorescência e fosforescência.

Procurei, ao longo destes três textos, deixar algumas ideias, alguns factos, alguns comentários. Repito que gostaria de sentir que estes textos são uma espécie de semente, de início de diálogo. Cabe agora aos leitores (espero que os tenha havido), a resposta.

Se consegui inquietar alguns espíritos, tanto melhor. O ensinar tem que ser, deve ser, um prazer. Foi com prazer que escrevi estas linhas.

Tive há pouco tempo contacto com um investigador que me contou que numa entrevista lhe perguntaram por que razão ele fazia investigação. Ele respondeu que o fazia "pour s'amuser». Pois foi chamado à pedra tempos depois. Disseram-lhe que a investigação devia ser levada a sério, muito a sério.

Já será uma aquisição do tom com que eu escrevi estes textos que o leitor saiba sem a menor dúvida de que lado eu me situo quanto a esse «muito a sério» na investigação. 


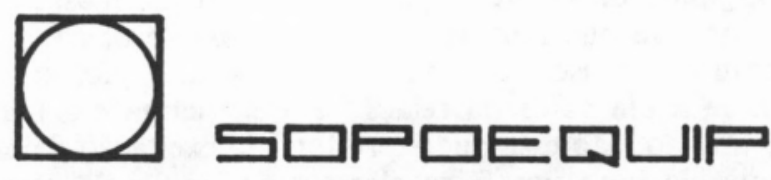

PRODUTOS E EQUIPAMENTOS PARA A INDÚSTRIA E LABORATORIOS LDA

\section{DINAMISMO - QUALIDADE}

\section{SERVIÇO}

\section{ESCOLHA - EFICIÊNCIA}

PEÇA-NOS A LISTA DAS NOSSAS REPRESENTADAS ALGUMA LHE INTERESSARÁ!

Estamos à distância do seu telefone... 